\title{
Pituitary Autoantibodies and Hypopituitarism
}

\author{
Patricia Anne Crock \\ Department of Paediatrics, John Hunter Hospital, Australia \\ Supported in part by a grant from the Alfred Hospital Research Fund, Alfred Hospital, Australia
}

\begin{abstract}
The clinical spectrum of autoimmune pituitary disease is still being defined. In the pediatric age group, autoimmune mechanisms have been postulated for some cases of growth hormone (GH) deficiency and the empty sella syndrome. The classical presentation in adulthood is of peripartum hypopituitarism associated with a pituitary mass and visual failure. Biopsy reveals lymphocytic infiltration of the pituitary, mainly with CD4+ T helper cells, and is termed lymphocytic hypophysitis. Secondary adrenal insufficiency is a prominent feature of the hypopituitarism and isolated adrenocorticotropin (ACTH) deficiency and the empty sella syndrome are thought to be endstages of the disease spectrum. There has been no specific pre-operative serological test for this condition.

We have developed a new assay based on immunoblotting, for evaluating autoantibodies in pituitary disease. The assay uses autopsy pituitaries which are homogenized and ultracentrifuged to give membrance and cytosolic fractions. Proteins are immunoblotted and reactivity of patient sera to autoantigens is detected using an alkaline-phosphatase conjugated second antibody.

A pituitary specific $45 \mathrm{kDa}$ membrane protein was identified by serum from a child with isolated GH dificiency and an empty sella. The target autoantigen in some cases of isolated ACTH deficiency appears to be a $49 \mathrm{kDa}$ cytosolic protein.
\end{abstract}

Key words: anti-pituitary autoantibodies, pituitary autoimmunity, empty sella syndrome, growth hormone deficiency, isolated adrenocorticotropin deficiency, immunoblotting

\section{Introduction}

This presentation is an overview of the clinicopathological spectrum of pituitary autoimmunity and of the field of antipituitary autoantibody testing. The development of a new assay for the detection of antipituitary autoan-

Correspondence: Dr. Patricia Anne Crock, Director of Paediatric Endocrinology and Diabetes, Department of Paediatrics, John Hunter Hospital, Locked Bag 1, Newcastle 2310, NSW, Australia tibodies is described using an immunoblotting method with discussion of its clinical applications.

\section{Pituitary Auto immune Disease}

\section{Histopathological Description}

The first recognised histological description of autoimmune pituitary disease was made in 1962 by Goudie and Pinkerton (1). 
They reported the case of a 22 year old woman with Hashimoto's thyroiditis who died postappendicectomy from secondary adrenal failure. The onset of symptoms of hypopituitarism had been temporally related to her second pregnancy, fourteen months previously. At autopsy, the lymphocytic infiltrate in her pituitary gland resembled that in her thyroid and the authors suggested that these two conditions shared an autoimmune basis related to "the reaction to antigens released during the puerperal involution of these glands". Review of Professor Goudie's original sections showed the diffuse lymphocytic infiltrate of the anterior pituitary with some extension into the adjacent dura mater. Immunohistochemical studies in our laboratory in collaboration with Dr. Wayne Hancock (Sandoz Center for Immunobiology, Deaconess Hospital, Harvard Medical School, Boston) showed that the infiltrate was predominantly composed of $\mathrm{T}$ cells. A CD4+ marker UCHL-1, showed that these lymphocytes were mainly CD4+ T helper cells, and a B cell marker, L26 showed that only a few of the cells were of this lineage. Other studies have also shown a significant CD4+ infiltrate (2-5) and one study that CD8+ cells were more common (6). However, it is possible that the nature of the infiltrate changes with time.

There appears to be a progression of histological changes in lymphocytic hypophysitis. In the early stages the gland is enlarged and infiltrated by lymphocytes, some of which may form follicles with germinal centres (2). Lymphocytic infiltration may extend into the dura as far as the cavernous sinuses, even causing internal carotid artery occlusion (7). The adenohypophysial cells atrophy and are destroyed
(8), often showing oncocytic change. Electron microscopy studies have shown lymphocytes interdigitating with pituitary cells (8, Crock et al. unpublished data). Later, there is fibrosis which gives the gland a characteristic yellowish colour and firm consistency at neurosurgical exploration, quite unlike pituitary adenomata (3). Although there may still be a pituitary mass at this stage, which may last many years, ultimately the gland shrinks in size and in some cases may leave an empty sella (9). Thus, end-stage lymphocytic hypophysitis probably accounts for some cases of the empty sella syndrome.

\section{Clinical Spectrum}

There are now nearly 100 cases of biopsyproven lymphocytic hypophysitis in the world literature. The advent of computed tomography (CT) and magnetic resonance imaging (MRI) scans has been associated with an increase in the number of reported cases. Lymphocytic hypophysitis cannot be distinguished from a pituitary adenoma by radiological imaging as both lesions cause a mass which will enhance with contrast (1012). However, there are some clinical features which make the diagnosis more likely and these will be discussed within the spectrum of disease presentation.

The most acute presentation recorded is a fatal adrenal crisis during labour (13), but patients may also present with sudden headache. Classically the presentation is as a pituitary mass associated with headache, visual symptoms and hypopituitarism in the last trimester of pregnancy or in the postpartum period $(8,11,15)$. Approximately fifty percent of cases have an association with preg- 


\section{Antipituitary Autoantibodies and Hypopituitarism}

nancy and only twelve cases have been recorded in men, the first case being described in 1987 (16). The striking feature of the hypopituitarism is the presence of adrenocorticotropin (ACTH) deficiency, which can be an isolated deficit $(2,17)$. By contrast, ACTH is usually the last hormone to be lost with pituitary tumours. There are some cases which appear to resolve spontaneously (18-22). Other, non-tumourous causes of hypopituitarism should be included in the differential diagnosis, the most important of these being Sheehan's syndrome (post-partum pituitary necrosis). It is likely that some cases of Sheehan's syndrome, in which there has not been major peri-partum blood loss, are due to unrecognized lymphocytic hypophysitis.

Another feature of lymphocytic hypophysitis which should arouse suspicion that the lesion is not a pituitary adenoma is its association with diabetes insipidus, which is rarely seen pre-operatively with pituitary tumours (23). The term infundibuloneurohypophysitis has been coined by Imura et al. (24) and it is unclear if this is a new entity or part of the spectrum. Other unusual presentations have included infertility (4), hyperprolactinemia (25), transient cranial nerve palsies (7), cavernous sinus involvement $(7,27)$ and internal carotid artery occlusion (20).

The histological and immunohistochemical studies described above and the incidence of coexistent autoimmune disease in up to 40 $\%$ of patients $(28,29)$, all support the concept of lymphocytic hypophysitis as one of the endocrine organ-specific autoimmune diseases. However until now, pituitary biopsy or hypophysectomy have been the only means of making this diagnosis definitively in a living patient. The need for a pre-operative serological diagnostic test is evident.

\section{Antipituitary Autoantibody Testing}

The detection of circulating autoantibodies is one of the criteria of autoimmunity and has proved more problematic in pituitary autoimmune disease than in other endocrine organ-specific autoimmune diseases. The ability to make a serological diagnosis with positive antipituitary autoantibodies would help to define the clinical spectrum of the disease and perhaps avoid neurosurgery in selected cases.

\section{Complement Fixation and Immunofluo- rescence Assays}

The first paper detailing antipituitary autoantibody activity was by Engelberth and Jezkova in 1965 who used a complement-fixation test but there was no objective endocrine data on the clinical state of these patients (30). Testing by immunofluorescence was developed by Bottazzo et al. in 1975 using fresh, frozen human pituitary tissue from hypophysectomies performed for breast cancer (31). Anti-pituitary prolactin cell autoantibodies were detected in 19 of 287 patients with polyglandular autoimmune disease, but again none of these patients had evidence of pituitary insufficiency (31). These autoantibodies were also said to be primate specific and of low titre.

Dr. Sugiura et al. from Sohgo Biomedical Laboratories have developed an immunofluorescence assay using AtT20 cells (a mouse pituitary ACTH-secreting cell line) and GH3 cells (a rat pituitary GH-and prolactin-producing cell line) (32). Reactivity to AtT20 cells 


\section{Crock}

was seen in five of five patients with isolated ACTH deficiency and $75 \%$ of patients with the primary empty sella syndrome (33). Professor Kobayashi et al. have demonstrated autoantibodies to AtT20 cells in 11 of 14 pregnant women just prior to delivery but this phenomenon decreased to 4 out of $14,(14 \%)$ by day 6 postpartum (34).

\section{Immunoblotting Method}

The original case which prompted this study was a boy aged 11 years, who presented growth failure over 2 years due to isolated $\mathrm{GH}$ deficiency. Apart from an empty sella turcica on CT scan of his head, no cause could be found. We postulated that atrophy of his pituitary gland could have been due to the end stage of an autoimmune process and set out to determine if antipituitary autoantibodies could be identified in his serum. The unavailability of fresh, frozen human pituitary tissue for immunofluorescence studies led to the search for an alternative approach.

\section{Immunoblotting Method}

This method for the detection of antipituitary autoantibodies has been published previously (35). In brief, human autopsy pituitary glands were obtained within 4-8 hours of death and frozen at $-70^{\circ} \mathrm{C}$. The glands were homogenised with a mixture of protease inhibitors, and centrifuged at $100,000 \times \mathrm{g}$ to give cytosolic and membrane fractions. The pituitary preparations were fractionated on sodium dodecyl sulfate (SDS) -polyacrylamide gel by electrophoresis and separated proteins transferred to Immobilon polyvinylidene difluoride (PVDF) transfer membranes. Immobilon strips were incubated with experimental or control serum diluted 1:50 in $1 \%$ skim milk powder in phosphate buffered saline (PBS) overnight at $4{ }^{\circ} \mathrm{C}$. Positive immunoreactivity was detected using goat anti-human IgG conjugated to alkaline phosphatase (BioRad) as the second antibody step. Strips were developed with 5-bromo-4-chloro-3 indolyl phosphate (BCIP) and nitro blue tetrazolium (NBT) (Bio Rad). Non-specific binding by second antibody alone was seen at approximately $50 \mathrm{kDa}$ and $25 \mathrm{kDa}$, the sizes of the heavy and light chains respectively of immunoglobulins from blood present in the pituitary tissue.

\section{Clinical Subjects}

We studied the prevalence of antipituitary autoantibodies as detected by immunoblotting, in 20 children with idiopathic GH deficiency, 15 children with acquired GH deficiency secondary to irradiation or surgery and 29 normal paediatric control subjects (35).

At this time we were also sent sera from three men (aged 44, 45 and 49 years) with isolated ACTH deficiency, one of whom had a partial empty sella on CT scan. One of these patients had been reported by Sauter et al. from Tufts University, Boston, to have autoantibodies directed against $200 \mathrm{~nm}$ secretory granules in rat corticotrophs using immunohistochemistry (36). Ethical approval for this study was given by the Human Ethics Committee of the Alfred Hospital, Prahran.

\section{Pituitary Membrane Autoantibodies}

None of the sera from normal pediatric subjects had significant reactivity to pituitary membrane antigens (35). The child with isolated GH deficiency and the empty sella 


\section{Antipituitary Autoantibodies and Hypopituitarism}

syndrome had autoantibody reactivity to a 45 $\mathrm{kDa}$ pituitary-specific membrane protein. This reactivity could not be demonstrated in serum which had been taken prior to recombinant GH treatment and which had been stored for many years at $-20^{\circ} \mathrm{C}$. Two children with idiopathic $\mathrm{GH}$ deficiency, previously treated with pituitary-extracted $\mathrm{GH}$, had autoantibodies to a $43 \mathrm{kDa}$ membrane protein that was also present in brain membrane fractions. Two children with radiation-induced hypopituitarism had autoantibodies to a $95 \mathrm{kDa}$ pituitary membrane protein. The clinicopathological significance of these autoantibodies is unclear. The induction of autoantibodies by irradiation has been reported (37) and it is possible that impurities in the pituitary-extracted GH used for therapy, "immunized" the two patients with reactivity to the $43 \mathrm{kDa}$ protein (35), although it was not seen in any of the other patients' sera. The empty sella syndrome has been associated with antipituitary autoantibodies detected by other methods (32, 33) and so our original case with reactivity to a $45 \mathrm{kDa}$ pituitary membrane protein may represent autoimmunemediated GH deficiency.

\section{Pituitary Cytosolic Autoantibodies}

Antipituitary autoantibodies of high titre $(>1: 1,000)$ were found in the sera of two of the three patients with isolated ACTH deficiency (38). Immunoreactivity was to a pituitary cytosolic protein of molecular weight $49 \mathrm{kDa}$ and was not found in the sera of any of the pediatric control patients (38). Isolated ACTH deficiency is a rare condition that has been reported in association with lymphocytic hypophysitis $(2,17)$ and the prediliction for corticotroph destruction in the latter has already been discussed above. It has also been reported with the empty sella syndrome as was seen in one of our cases $(39,40)$.

The high titre autoantibodies detected by immunoblotting are supporting evidence that isolated ACTH deficiency and the empty sella syndrome both have an autoimmune basis. Further characterization of the $49 \mathrm{kDa}$ autoantigen targetted by these autoantibodies is currently in progress.

\section{Acknowledgements}

Professor Goudie kindly provided further sections from his original case report and these are gratefully acknowledged. The expert assistance of Ms. Julie Maguire and Dr. Wayne W. Hancock for the immuno-histochemical study of these sections was greatly appreciated. Dr. Hancock is currently at the Sandoz Center for Immunobiology, Deaconess Hospital, Harvard University, Boston, USA. Sera from the three patients with isolated ACTH deficiency were generously provided by Dr. D. Topliss, Alfred Hospital, Melbourne, Australia; Drs. N. Sauter and R. Lechan, Tufts University, Boston, USA; and Drs. N. McLean, A. Shlossberg and R. Rittmaster, Halifax, Nova Scotia, Canada.

\section{References}

1. Goudie RB, Pinkerton PH. Anterior hypophysitis and Hashimoto's disease in a young woman. J Pathol Bacteriol 1962; 83: 584-5.

2. Jensen MD, Handwerger BS, Scheithauer BW, Carpenter PC, Mirakian R, Banks 
PM. Lymphocytic hypophysitis with isolated corticotropin deficiency. Ann Intern Med 1986; 105: 200-3.

3. Miura M, Ushio Y, Kuratsu J, Ikeda J, Kai Y, Yamashiro S. Lymphocytic adenohypophysitis: Report of Two Cases. Surg Neurol 1989; 32: 463-70.

4. McCutcheon IE, Oldfield EH. Lymphocytic adenohypophysitis presenting as infertility. Case report. J Neurosurg 1991; 74(5): 821-6.

5. Hashimoto M, Yanaki T, Nakahara N, Masuzawa T. Lymphocytic adenohypophysitis: an immunohistochemical study. Surg Neurol 1991; 36(2): 137-44.

6. Parent AD, Cruse JM, Smith EE, Smith RR. Lymphocytic Hypophysitis-Autoimmune Reaction? Adv Biosciences 1988; 69 : 465-9.

7. Nussbaum CE, Okawara SH, Jacobs LS. Lymphocytic hypophysitis with involvement of the cavernous sinus and hypothalamus. Neurosurgery 1991; 28(3): 440-4.

8. Asa SL, Bilbao JM, Kovacs K, Josse RG, Kreines K. Lymphocytic hypophysitis of pregnancy resulting in hypopituitarism: a distinct clinicopathologic entity. Ann Intern Med 1981; 95: 166-71.

9. Brandes JC, Cerletty JM. Pregnancy in lymphocytic hypophysitis: case report and review. Wis Med J 1989; 88(11): 29-32.

10. Ahmadi J, Meyers GS, Segall HD, Sharma OP, Hinton DR. Lymphocytic adenohypophysitis: contrast-enhanced MRI imaging in five cases. Radiology 1995; 195(1): 30-4.

11. Baskin DS, Townsend JJ, Wilson Cb. Lymphocytic adenohypophysitis of pregnancy simulating a pituitary adenoma: A distinct pathological entity. Report of two cases. J Neurosurg 1982; 56: 148-53.

12. Hungerford GD, Biggs PJ, Levine JH, Shelley BE Jr, Perot PL, Chambers JK. Lymphoid adenohypophysitis with radiologic and clinical findings resembling a pituitary tumour. AJNR Am J Neuroradiol 1982; 3: 444-6.

13. Gal R, Schwartz A, Gukovsky-Oren S, Peleg D, Goldman J, Kessler E. Lymphoid hypophysitis associated with sudden maternal death: Report of a case and review of the literature. Obstet Gynecol Surv 1986; 41: 619-21.

14. Okamoto T, Moriyama E, Mizukawa N. Lymphoid adenohypophysitis. Act Pathol Jpn 1986; 36: 751-6.

15. Feigenbaum SL, Martin MC, Wilson CB, Jaffe RB. Lymphocytic adenohypophysitis: a pituitary mass lesion occurring in pregnancy. Proposal for medical treatment. Am J Obstet Gynecol 1991; 164: 1549-55.

16. Guay AT, Agnello V, Tronic BC, Gresham DG, Freidberg SR. Lymphocytic hypophysitis in a man. J Clin Endocrinol Metab 1987; 64: 631-4.

17. Richtsmeier AJ, Henry RA, Bloodworth JMB, Ehrlich EN. Lymphoid hypophysitis with selective adrenocorticotropic hormone deficiency. Arch Intern Med 1980; 140: 1243-5.

18. Castle D, De Villiers JC, Melvill R. Lymphocytic Adenohypophysitis. Report of a Case with Demonstration of Spontaneous Tumour Regression and a Review of the Literature. Br J Neurosurg 1988; 2: 401-6.

19. Bevan JS, Othman S, Lazarus JH, Parkes $\mathrm{AB}$, Hall R. Reversible adrenocorti- 
cotrophin deficiency due to probable autoimmune hypophysitis in a woman with postpartum thyroiditis. J Clin Endocrinol Metab 1992; 74(3): 548-52.

20. Ikeda H, Okudaira Y. Case reports. Spontaneous regression of pituitary mass in temporary association with pregnancy. Neuroradiology 1987; 29: 488-92.

21. McGrail KM, Beyerl BD, Black PM, Klibanski A, Zervas NT. Lymphocytic adenohypophysitis of pregnancy with complete recovery. Neurosurgery $1987 ; 20$ : 791-3.

22. Zeller JR. Cerletty JM, Rabinovitch RA, Daniels D. Spontaneous regression of a postpartum pituitary mass demonstrated by computed tomography. Arch Intern Med 1982; 142: 373-4.

23. Ito K, Mukawa J, Miyagi $\mathrm{K}$, Takara $\mathrm{E}$, Mekaru S, Ishikawa Y, et al. Lymphocytic adenohypophysitis with sudden onset of diabetes insipidus in menopausal femalecase report. Neurol Med Chir (Tokyo) 1992; 32(6): 346-50.

24. Imura $H$, Nakao K, Shiamtsu A, Ogawa $Y$, Sando T, Fujisawa I, at al. Yamabe H. Lymphocytic Infundibuloneurohypophysitis as a cause of central diabetes insipidus. N Engl J Med 1993; 329: 683-9.

25. Cebelin MS, Velasco ME, De Las Mulas JM, Druet RL. Galactorrhoea associated with lymphocytic adenohypophysitis. Case Report. Obstet Gynaecol 1981; 88: 675-80.

27. Supler ML, Mickle JP. Lymphocytic hypophysitis: report of a case in a man with cavernous sinus involvement. Surg Neurol 1992; 37(6): 472-6.

28. Cosman F, Post KD, Holub DA, Wardlaw
SL. Lymphocytic Hypophysitis. Report of 3 New Cases and Review of the Literature. Medicine 1989; 68(4): 240-56.

29. Mazzone T, Kelly W, Ensinck J. Lymphocytic hypophysitis. Associated with antiparietal cell antibodies and vitamin B12 deficiency. Arch Intern Med 1983; 143: 1794-5.

30. Engelberth O, Jezkova Z. Autoantibodies in Sheehan's syndrome. Lancet 1965; 1: 1075.

31. Bottazzo GF, Pouplard A, FlorinChristensen A, Doniach D. Autoantibodies to prolactin-secreting cells of human pituitary. Lancet 1975; ii: 97-101.

32. Sugiura M, Hashimoto A, Shizawa M, Tsukada M, Maruyama S, Ishido T, et al. Heterogeneity of anterior pituitary cell antibodies detected in insulin-dependent diabetes mellitus and adrenocorticotropic hormone deficiency. Diabetes Res 1986; 3: 111-4.

33. Komatsu M, Kondo T, Yamauchi K, Yokokawa N, Ichikawa K, Ishihara M, et al. Antipituitary Antibodies in Patients with the Primary Empty Sella Syndrome. J Clin Endocrinol Metab 1988; 67: 633-8.

34. Kobayashi I, Inukai T, Kikuchi T, Nishino M, Sugiura M, Hashimoto A. Studies on postpartum pituitary autoimmunity: changes in pituitary antibodies. 10th International Thyroid Conference, The Hague, Netherlands. 1991: 403. (Abstract)

35. Crock PA, Salvi M, Miller A, Wall J, Guyda H. Detection of Anti-pituitary Autoantibodies by Immunoblotting. J Immunol Methods 1993; 162: 31-40.

36. Sauter NP, Toni R, McLaughlin CD, Dyess EM, Kritzman J, Lechan R. Isolated 


\section{Crock}

Adrenocorticotrophin Deficiency Associated with an Autoantibody to a Corticotroph Antigen that is not Adrenocorticotrophin or other Proopiomelanocortin-derived Peptides. J Clin Endocrinol Metab 1990; 70: 1391-7.

37. Etzrodt H, Eier H, Knöringer P, Kratzsch G. Immunohypophysitis, a cause of hypopituitarism? Acta Endocrinol Suppl (Copenh) 1984; 264:137. (Abstract)

38. Crock P, Salvi M, Miller A, Wall J, Guyda $H$. Identification of a $49 \mathrm{kd}$ Autoantigen in Isolated Adrenocorticotropin (ACTH) Deficiency. Ninth International Congress of Endocrinology, Nice, France: 01, 31,062. (Abstract)

39. Komatsu M, Aizawa T, Shinoda T, Yamada T, Mochizuki T. Case Report: ACTH Deficiency and TSH Hypersecretion in a Patient with Empty Sella Turcica. Am J Med Sci 1989; 297(3): 186-9.

40. Okado K, Ishikawa S, Saito T, Kumakura S, Sakamoto Y, Kuzuya T. A Case of Partial Hypopituitarism with Empty Sella Following Normal Course of Pregnancy and Delivery. Endocrinol Japon 1986; 33(1): 117-23. 